\title{
D. ELOY BENITO RUANO, IN MEMORIAM
}

\section{ENRIQUE CANTERA MONTENEGRO}

COORDINADOR DE ESPACIO, TIEMPO Y FORMA.

SERIE III. HISTORIA MEDIEVAL

DOI: http://dx.doi.org/10.5944/etfiii.28.2015.14862 


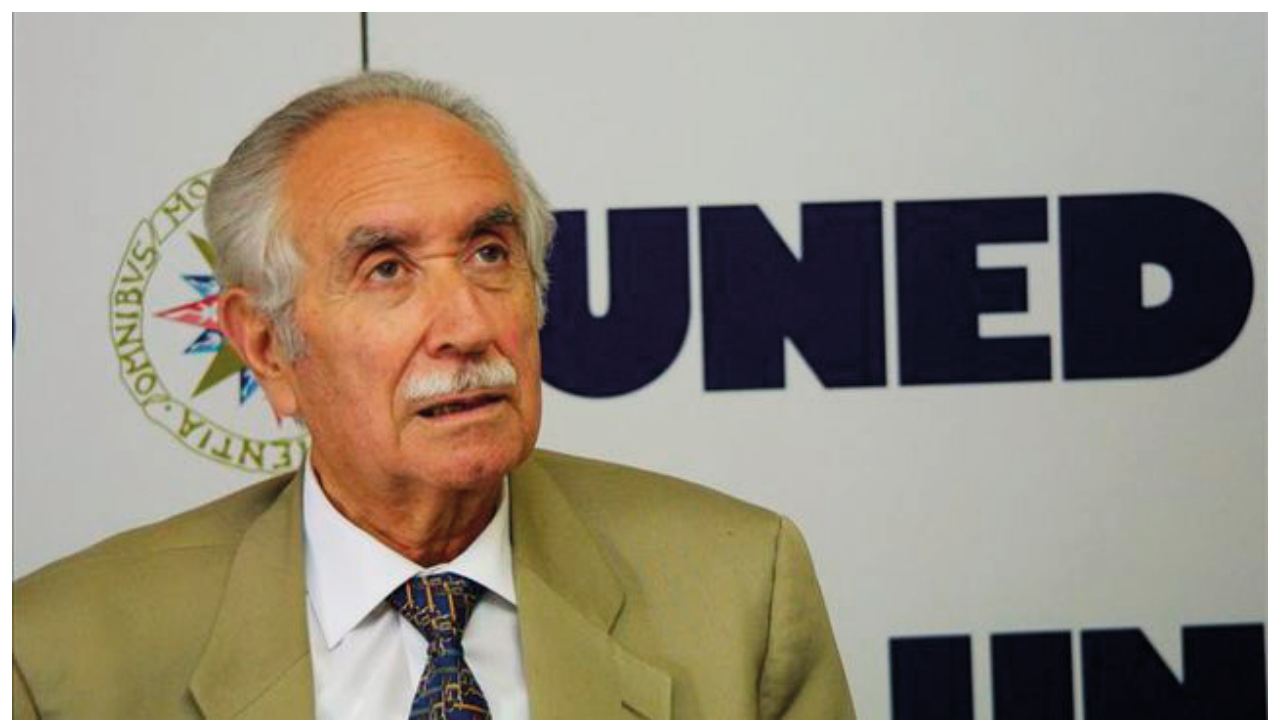


EL PASADO DÍA 22 DE ABRIL DE 2014 fallecía en Oviedo D. Eloy Benito Ruano, quien durante varios años fue catedrático de Historia Medieval en la Universidad Nacional de Educación a Distancia y director del Departamento de Historia Medieval y Moderna. Como integrante de su Comité de Redacción, formó parte del equipo fundacional de la revista Espacio, Tiempo y Forma. Revista de la Facultad de Geografía e Historia de la UNED, que inició su andadura en el año i988. A D. Eloy se debe, precisamente, el nombre de la revista, en el que se aúnan la Geografía, la Historia y la Historia del Arte, como expresión patente de los diversos campos científicos que constituyen la esencia de la Facultad de Geografía e Historia de la UNED, en cuyo seno nacía esta publicación. Integrada por siete series, la tercera de ellas está dedicada a la Historia Medieval y, precisamente, sus dos primeros números, correspondientes a los años I988 y I989, constituyeron sendos volúmenes de homenaje al Profesor Benito Ruano con motivo de su jubilación académica.

Con este triste motivo, el Comité de Redacción de la revista Espacio, Tiempo y Forma. Serie 11I. Historia Medieval y el Departamento de Historia Medieval y Ciencias y Técnicas Historiográficas de la UNED desean hacer expresión pública del sentimiento de gratitud, respeto y admiración que profesan hacia la persona y la trayectoria académica y profesional de D. Eloy Benito Ruano, dedicando a su Memoria unas breves notas acerca de su amplia y dilatada trayectoria, a través de las que queda constancia de su ingente contribución a la Historia Medieval, a la Universidad española en su conjunto y a la progresiva integración de la comunidad de historiadores españoles en las coordenadas de la historiografía internacional.

\section{๗ָे}

El Profesor Eloy Benito Ruano nació en Madrid, el día I de diciembre (festividad de San Eloy) de i92I. En esta ciudad transcurrió su infancia y su juventud, hasta que se trasladó a Tenerife por motivos laborales, compaginando su actividad profesional como inspector de Policía con los estudios de Filosofía y Letras en la Universidad de La Laguna. Vuelto a Madrid, concluyó sus estudios de licenciatura en I948, en la Universidad Central, con premio extraordinario. Y en esta misma Universidad se doctoró unos años más tarde, en I956, también con premio extraordinario, con una tesis en la que estudió la vida política de la ciudad de Toledo en el siglo xv. Este estudio fue merecedor en I960 del premio «Raimundo Lulio», y fue publicado al año siguiente por el Consejo Superior de Investigaciones Científicas con el título de Toledo en el siglo xV. Vida política (Madrid, I96r).

Los primeros pasos de su dilatada carrera docente los dio en la Facultad de Filosofía Letras de la Universidad Central de Madrid, en la que desempeñó los puestos de Profesor Ayudante (I948-I958) y de Profesor Adjunto de Historia General de España (I958-I964). Una actividad docente que compaginó desde el 
año I956 con la de Colaborador en el Instituto de Historia «Jerónimo Zurita» del Consejo Superior de Investigaciones Científicas, en el que desempeñó diversas tareas, entre ellas la de secretario de la revista Hispania desde el año I958.

En I964 obtuvo, por oposición, la cátedra de Historia General de España de la Universidad de Oviedo, en la que permaneció durante diecisiete años, desarrollando una intensa labor académica, científica y de gestión universitaria marcada por la excelencia. Así, en su etapa ovetense fue director del Colegio Mayor «San Gregorio» (I964-I973) y desempeñó los cargos de secretario (I964) y decano (I977) de la Facultad de Filosofía y Letras. En 1972 se le encargó la creación del Colegio Universitario de León, que nacía bajo dependencia orgánica de la Universidad de Oviedo, y fue su director desde 1972 hasta su transformación en Universidad propia en el año I980, siendo nombrado entonces decano en funciones de su Facultad de Filosofía y Letras durante el curso académico i980-8I.

Asimismo fue director del Departamento de Historia Medieval de la Universidad de Oviedo desde su creación en el año i966. De su paso por este cargo, y como mejor prueba de su capacidad para la innovación, quedaron la puesta en marcha de la revista Asturiensia Medievalia, en el año I972, y el impulso dado a diversas publicaciones monográficas centradas, en buena medida, en el estudio de la Edad Media asturiana; el volumen de homenaje que le dedicó la revista Asturiensia Medievalia en I985-1986 es expresión viva de un Magisterio que dejó huella profunda en la Universidad de Oviedo.

A comienzos del curso académico I98I-82 accedió por concurso de traslado a la Universidad Nacional de Educación a Distancia, donde desempeñó la última etapa de su vida académica. En la UNED fue director, sucesivamente, de los departamentos de Historia Medieval y de Historia Medieval y Moderna, e intervino en la creación y puesta en marcha de la revista Espacio, Tiempo y Forma, editada por la Facultad de Geografía e Historia de esta Universidad. En septiembre de I987, y como resultado de una absurda e injusta disposición administrativa que anticipaba la edad de jubilación del profesorado universitario, D. Eloy Benito Ruano hubo de jubilarse de forma prematura, si bien siguió vinculado a la UNED y a su Departamento de Historia Medieval, como Catedrático Emérito, hasta el año I997. Y aún después de esta fecha siguió interviniendo de forma activa en el curso organizado todos los años por el Departamento de Historia Medieval y Ciencias y Técnicas Historiográficas en el marco de los Cursos de Verano de la UnED de Ávila.

El 7 de mayo de 1986 fue elegido Académico de Número de la Real Academia de la Historia (Medalla n. ${ }^{\circ} 33$ ), tomando posesión el 22 de mayo de I988, con un discurso de ingreso que tuvo por título De la alteridad en la Historia. Desde 1990 fue Secretario perpetuo de la Academia, desarrollando una tarea sumamente eficaz, en la que no sólo atendió puntualmente al buen funcionamiento de esta institución, sino que también fue impulsor de nuevas colecciones editoriales, como «Clave Historial», y de diversos ciclos de conferencias que se materializaron posteriormente en volúmenes de gran interés y éxito editorial. Uno de estos 
ciclos, titulado Reflexiones sobre el ser de España, en el que intervinieron veintidós de los académicos por entonces pertenecientes a esta institución, dio lugar a una publicación con el mismo título que fue galardonada con el Premio Nacional de Historia, que concede el Ministerio de Educación y Cultura, por fallo emitido el día I6 de noviembre de i998. Son también buen ejemplo de estos ciclos los titulados España, cambio de siglo, en conmemoración del Centenario del noventa y ocho, y Tópicos y realidades de la Edad Media, que dio lugar a dos gruesos volúmenes con cerca de veinte colaboraciones.

En el año I988 sucedió al profesor D. Emilio Sáez Sánchez al frente de la Sociedad Española de Estudios Medievales, permaneciendo en este cargo hasta el año 200I, un tiempo durante el que impulsó importantes novedades en la marcha de la Sociedad que contribuyeron a consolidar su estructura. En I99I fue creada, en buena medida por iniciativa suya, la revista Medievalismo, que en la actualidad es una de las más prestigiosas publicaciones periódicas del medievalismo español, plenamente acomodada a los criterios de calidad científica que rigen en la actualidad. En el año 200I, al ser relevado en la presidencia de la SEEM, fue distinguido con el nombramiento de Presidente Honorario de esta Sociedad. En diciembre del año 20Io, la SEEM rindió a D. Eloy Benito un emotivo homenaje en la sede del Centro de Ciencias Humanas y Sociales del csic, en el que se le hicieron entrega de dos gruesos volúmenes de colaboraciones dedicadas a su persona, que bajo el título de Homenaje al Profesor Eloy Benito Ruano, fueron editados por la SEEM, el csic y la Editorial de la Universidad de Murcia.

D. Eloy desarrolló también desde muy pronto una gran labor de proyección científica internacionalista, que tiene su mejor expresión en la activa participación en reuniones, congresos y cursos fuera de nuestras fronteras y, muy especialmente, en la intensa labor que desarrolló en el seno del Comité Español de Ciencias Históricas, del que fue, sucesivamente, vicesecretario, secretario, vicepresidente y presidente. Este último cargo lo desempeñó desde el año I975 hasta su relevo reglamentario por D. Manuel Espadas Burgos en 1993, siendo nombrado entonces Presidente Honorario del Comité. Participó activamente desde el año I955 en los Congresos Internacionales de Ciencias Históricas celebrados en distintas ciudades del mundo, y en el año I99o estuvo al frente del comité organizador del xvıI Congreso Internacional que tuvo lugar en Madrid, reuniendo a alrededor de dos mil quinientos participantes llegados desde los más diversos países. El enorme éxito organizativo de este memorable acontecimiento propició su nombramiento como vicepresidente del Comité Internacional de Ciencias Históricas para el lustro de I990 a I995.

El Profesor Eloy Benito Ruano recibió a lo largo de su vida innumerables distinciones, entre las que podrían ser destacadas las siguientes: Doctor Honoris Causa por las Universidades de León y Oviedo; Académico de Mérito de la Academia Portuguesa de la Historia; Miembro de la Academia de San Dámaso, de la Academia de Doctores, del Instituto de Estudios Madrileños, del Instituto de Estudios 
Asturianos y de la Associazione degli Storici Europei, de la que fue presidente; y Correspondiente del Instituto de Estudios Canarios y de la Real Academia de Bellas Artes y Ciencias Históricas de Toledo.

Su producción historiográfica es amplia, diversa y, sobre todo, de gran calidad científica. Siguiendo al Profesor Juan Ignacio Ruiz de la Peña en las semblanzas que sobre D. Eloy Benito fueron publicadas en las revistas Espacio, Tiempo y Forma. Serie III. Historia Medieval (I, I988) y Medievalismo (II, 200I), con ocasión de su jubilación en la UNED y de su relevo en la presidencia de la Sociedad Española de Estudios Medievales, respectivamente, su obra podría ser clasificada, a grandes rasgos, en las siguientes líneas de investigación:

* Investigaciones centradas en un marco regional, entre las que cabe encuadrar algunos de sus primeros trabajos de investigación sobre historia canaria e historia toledana, que alcanzarían su obra culminante en el libro titulado Toledo en el siglo XV. Vida política (Madrid, I96I) que, como antes se apuntaba, tuvo su origen en el estudio que constituyó su tesis doctoral.

* Dentro de esta misma línea habría que dedicar un apartado muy especial a sus investigaciones sobre historia asturiana, de las que podrían ser destacados sus estudios sobre las Hermandades en Asturias durante la Edad Media (Oviedo, I97I) o los capítulos sobre la época de la monarquía asturiana del volumen IV de la Historia de Asturias (Oviedo, I977), una obra colectiva en cuya edición tuvo una activa intervención el Profesor Benito Ruano.

* Estudios de contenido biográfico, que son, muy posiblemente, aquellos en los que el elegante estilo literario que caracteriza la escritura de D. Eloy Benito alcanza su mejor expresión. Y entre todos ellos merece una mención especial una de sus obras pioneras, la que dedicó a Los infantes de Aragón (Madrid, I952), así como el volumen que, con el título de Gente del siglo XV (Madrid, I998), recoge varios artículos dedicados a distintos protagonistas de los tiempos medievales, como el labrador «más astroso» de Cuéllar, los mercaderes Pero de Monsalve y Gómez Arias, el escalador Ortega, el poeta Lope de Stúñiga o algunos extranjeros participantes en la guerra de Granada.

* Investigaciones sobre Órdenes Militares, Reconquista y Cruzada, con una atención muy particular a la Orden de Santiago. En esta línea podría ser destacada su magnífica monografía sobre La banca toscana y la Orden de Santiago durante el siglo XIII (Valladolid, I96I), así como sus Estudios santiaguistas (León, I978), un libro éste en el que se recopilan varias de sus contribuciones al tema.

* Estudios acerca de los judeoconversos castellanos, que han constituido un tema recurrente a lo largo de toda la trayectoria investigadora de D. Eloy, y entre los que habría que destacar algunos trabajos dedicados a la revuelta toledana de I449 y al subsiguiente debate doctrinal en torno a la integración de los conversos en la sociedad cristiana, que serían reunidos en el volumen 
titulado Los orígenes del problema converso (Barcelona, I976), reeditado hace unos años por la Real Academia de la Historia (Madrid, 200I), con actualización y ampliación de sus contenidos.

Es mucho más lo que cabría decir sobre la figura humana y la trayectoria profesional y científica del Profesor Eloy Benito Ruano. Pero creo que todo ello se condensa de forma admirable en las líneas que ponen fin a la nota necrológica que, firmada por el Profesor Miguel Ángel Ladero Quesada, publicó el diario $A B C$ el día 25 de abril de 2015 (p. 92):

\footnotetext{
Eloy tenía excelentes dotes personales: era muy trabajador, sabía organizar y coordinar, tenía el genio vivo y, a la vez, apacible, cultivaba una gran agudeza intelectual servida por la bonhomía y el deseo de ayudar a los otros; todo en él llamaba fácilmente a la sociabilidad, la amistad y el entendimiento. Ha sido la suya una vida profesional plena, dedicada a la Historia, y así lo recordaremos e imaginaremos sus amigos, en esa plenitud recuperada para siempre.
}

Es muy difícil encontrar palabras que definan mejor la personalidad de D. Eloy y que, por ello, puedan explicar de forma más nítida el sentimiento de orfandad que nos embarga a quienes tuvimos el privilegio de disfrutar de su proximidad y de aprender con su ejemplo. Que descanse en la Paz Eterna quien a lo largo de toda su vida buscó siempre el entendimiento y la concordia. 